
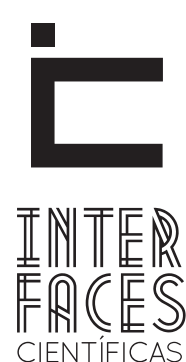

HUMANAS E SOCIAIS

ISSN IMPRESSO 2316-3348

E-ISSN 2316-3801

DOI - 10.17564/2316-3801.2018v7n1p59-70

\title{
ANTHONY GIDDENS E PIERRE BOURDIEU: É POSSÍVEL FALAR EM PÓS-ESTRUTURALISMO?
}

\author{
ANTHONY GIDDENS AND PIERRE BOURDIEU: IS IT POSSIBLE TO SPEAK IN POST STRUCTURALISM? \\ ANTHONY GIDDENS Y PIERRE BOURDIEU: ÉS POSIBLE HABLAR EN POST-ESTRUCTURALISMO?
}

Mateus Bender ${ }^{1}$

Gabriel Bandeira Coelho²

\section{RESUMO}

O objetivo do artigo é debater o quadro teórico-metodológico de análise da vida social formulado por Pierre Bourdieu e Anthony Giddens. Embora esses autores neguem a denominação de pós-estruturalistas, busca-se aproximar os pressupostos teóricos à vertente filosófica/sociológica, contribuindo ao debate da teoria social contemporânea. Após debater acerca da definição e conceitualização do movimento pós-estruturalista, em um segundo momento analisa-se a teoria social de Pierre Bourdieu, buscando destacar suas possíveis aproximações teóricas/filosóficas com o movimento. Posteriormente, é destacada a teoria da estruturação e a possibilidade de proximidade teórica de Anthony Giddens com a perspectiva pós-estruturalista. Conclui-se que seus elementos epistemológicos, metodológicos e teóricos estão muito mais próximos de uma perspectiva pós-estruturalista do que qualquer outra vertente do pensamento sociológico.

\section{PALAVRAS-CHAVE}

Pós-Estruturalismo. Pierre Bourdieu. Anthony Giddens. 


\section{ABSTRACT}

The purpose of this article is to discuss the theoretical-methodological framework of social life analysis formulated by Pierre Bourdieu and Anthony Giddens. Although these authors deny the denomination of poststructuralists, it seeks to approximate the theoretical presuppositions to the philosophical / sociological aspect, contributing to the debate of contemporary social theory. After discussing the definition and conceptualization of the post-structuralist movement, in a second moment Pierre Bourdieu's social theory is analyzed, seeking to highlight its possible theoretical / philosophical approaches to the

\section{RESUMEN}

El objetivo de este artículo es discutir el marco teórico y metodológico para análisis de la vida social formulado por Pierre Bourdieu y Anthony Giddens. Aunque los autores nieguen la denominación postestructuralista, buscase acercar los supuestos teóricos a los aspectos filosóficos/sociológicos, lo que contribuye a la discusión de la teoría social contemporánea. Después de la discusión sobre la definición y conceptualización del movimiento postestructuralista, en una segunda fase se presenta el análisis de la teoría social de Pierre Bourdieu, tratando de poner de relieve sus enfoques teóricos/filosóficas a la circulación. Más tarde, pues- movement. Subsequently, the theory of structuration and the possibility of Anthony Giddens' theoretical proximity with the poststructuralist perspective is highlighted. It is concluded that its epistemological, methodological and theoretical elements are much closer to a poststructuralist perspective than any other strand of sociological thought.

\section{KEYWORDS}

Post-structuralism. Pierre Bourdieu. Anthony Giddens. to de relieve una teoría de la estructura y una posibilidad teórica de la proximidad Anthony Giddens con una perspectiva postestructuralista. Se llega a la conclusión de que sus elementos epistemológicos, metodológicos y teóricos son mucho más cerca de una perspectiva postestructuralista que cualquier otro aspecto del pensamiento sociológico.

\section{PALABRAS CLAVE}

Post-estructuralismo. Pierre Bourdieu. Anthony Giddens. 


\section{INTRODUÇ̃̃̃O}

No presente artigo temos como objetivo, de forma geral, apresentar os quadros teórico-metodológicos de análise da vida social formulados por Pierre Bourdieu e Anthony Giddens. Dessa maneira, nosso intuito é destacar as possíveis relações entre os pressupostos teóricos dos referidos autores à vertente filosófica/sociológica conhecida como Pós-Estruturalismo. Diante disto, cientes de que ambos os autores rejeitariam o rótulo de "pós-estruturalista”, nossa intenção não é de nomeá-los como tal, mas sim, propor um debate que contribua para pensarmos, de outra maneira, como a sociologia a partir da década de 1960 , tem se comportado frente ao universo social contemporâneo.

Neste sentido, apresentaremos a discussão proposta por Bourdieu, sobre a dicotomia ação versus estrutura, subjetivo versus objetivo - muito presente nas contendas epistemológicas da primeira metade do século XX. Utilizando os conceitos de habitus e de campo, entre outros não menos importantes, Bourdieu forma uma rede de interações que orienta a sociologia relacional (explicação), a partir da análise (geralmente fundada em estatísticas) das relações internas do objeto social, realizando um entrelaçamento entre a teoria do habitus e do campo, no qual uma é meio e consequência da outra (VANDENBERGHE, 2010).

Outro autor considerável na contemporaneidade, o sociólogo britânico Anthony Giddens, também se aproxima das características pós-estruturalistas. Contribuindo largamente para a interpretação da teoria social clássica, o sociólogo britânico introduziu o termo "estruturação" para designar a dependência mútua entre a agência humana (capacidade racional de realizar atos) e a estrutura social. Para Giddens, as estruturas sociais não possuem barreiras repressoras para a ação humana, tampouco impedem a capacidade racional da ação do agente social, mas pelo contrário, essas estruturas sociais estão intimamente ligadas à produção e reprodução da ação. Diante desta contrariedade à rigidez da estrutura, impondo aos sujeitos uma racionalidade, Giddens critica o estruturalismo e aproxima-se das características pós-estruturais.

Frente ao exposto, e, com o intuito de apresentarmos aquilo que pode ser visto como influências, reflexos pós-estruturalistas nas teorias de Pierre Bourdieu e Anthony Giddens, o presente artigo divide-se em três secções. Primeiramente, propomos um debate acerca da definição, conceitualização do movimento pós-estruturalista. Em um segundo momento, ao analisarmos as teorias de Pierre Bourdieu, buscaremos destacar suas possíveis aproximações teóricas/filosóficas com o movimento pós-estruturalista. Do mesmo modo, destacaremos, na terceira e última secção, a teoria da estruturação, com o objetivo de sublinhar uma possibilidade de proximidade teórica de Anthony Giddens com a perspectiva do Pós-Estruturalismo.

\section{AFINAL, O QUE É PÓS-ESTRUTURALISMO?}

Ao falarmos de Pós-Estruturalismo, não podemos deixar de elencar o cenário anterior ao seu surgimento, principalmente o contexto epistemológico que emergia no século passado. Neste sentido, o século XX foi, sem dúvida, marcado por inúmeros esforços teóricos e metodológicos que buscavam, por sua vez, explicar a dinâmica social decorrente das transformações sociais desse período. 0 referido século caracterizou-se por um contexto de grandes mudanças tanto na Ciência como na Sociedade. As duas Guerras Mundiais, a II Revolução Industrial, as descobertas da física quântica, e a teoria da relatividade ${ }^{3}$ entre outros, são eventos que demonstram a alta dinamicidade do tecido social neste século.

\footnotetext{
3 Segundo Lima (2006 p. 139), a física quântica surge como um dos maiores componentes do paradigma da complexidade, evidenciando "o princípio da historicidade e do tempo, dentro dos princípios paradigmáticos”. A Teoria Geral da Relatividade, do físico Albert Einstein, mesmo que considerada física clássica, também teve um importante papel nas transformações da Ciência, no início do século XX.
} 
Dentre os enfoques epistemológicos que emergi$\mathrm{ram}^{4}$, sobretudo na primeira metade do século XX, e que são centrais para entender os aspectos teóricos de Anthony Giddens e Pierre Bourdieu, destacam-se o existencialismo, com sua sociologia humanista, representado por Jean-Paul Sartre e o estruturalismo, caracterizado pelo seu determinismo estrutural (Sociologia da Estrutura), tendo como representante, o antropólogo francês, Claude Levi-Strauss.

Assim, o existencialismo tem por base a perspectiva de que não existe nada anterior ao ser, ou seja, somente o ser pode doar sentido ao mundo. Nestes termos, somente ele (o ser) significa o mundo. De certa forma, é uma ideia fenomenológica que, como pano de fundo, utiliza a autonomia cartesiana do sujeito, enfatizando o caráter humanista e a importância da ação individual para os existencialistas (Fenomenologia social). Já o estruturalismo - tendo como alicerce a linguística de Ferdinand Saussure objetivava garantir para si, por meio de leis gerais, o estatuto de Ciência no interior das ciências da humanidade (RODRIGUES, 2006).

Neste sentido, podemos identificar os reflexos do positivismo nesta corrente teórica, pois Levi-Strauss desejava, a partir de generalizações, tal como a física nuclear, fixar o estruturalismo na agenda cientifica da primeira metade do século XX. De modo geral, o estruturalismo advoga por uma explicação total dos fenômenos a partir de estruturas inconscientes, contrapondo-se à Sociologia da ação e fundando, com isso, uma Sociologia da estrutura.

Frente ao exposto, é importante ressaltarmos que até o fim da década de 1960, os embates teóricos travavam-se em torno do dualismo entre ação e estrutura. Os sociólogos da ação, de modo geral, colocavam o ator individual no papel de protagonista na trama social caracterização do processo ativo do agente frente à sociedade. Já para os representantes da sociologia da

4 É importante notar que novos pressupostos teóricos vão surgindo em função da crise dos postulados clássicos (Durkheim, Weber e Marx). Além disso, o funcionalismo de Robert Merton, o Estrutural funcionalismo de Talcolt Parsons e o pragmatismo da Escola de Chicago são destaques na história da Sociologia do Século XX. Para uma ampla compreensão do desenvolvimento nesse período, ver Cuin e Gresle (1994). estrutura, as ações individuais eram, em sua totalidade, resultados da estrutura social. Em outros termos, a ação era um reflexo estrutural e, por conta disso, o indivíduo tornava-se passivo frente à sociedade.

No entanto, foi a partir do evento denominado "maio de 1968 " temológicos, com o objetivo de articular ação e estrutura, surgiram para pôr fim ao que poderíamos denominar de "falsos dualismos". Esse movimento intelectual, o qual emerge do interior do próprio estruturalismo, na década de 1960, fora rotulado pelos norte-americanos de "Pós-Estruturalismo". É com base nisto que Michael Peters (2000) argumenta que o pós-estruturalismo nada mais é que uma crítica ao estruturalismo realizada a partir de seu interior, voltando, assim, argumentos estruturalistas contra o próprio estruturalismo.

Com efeito, muitos teóricos que poderiam ser considerados estruturalistas, perceberam a efervescência ocasionada pelo maio de 1968 e se perguntaram: como que atores sociais que são meros reflexos das dinâmicas estruturais podem sair às ruas para protestar e reivindicar mudanças na própria estrutura? A partir deste momento, sobretudo, no início da década de 1970, podemos dizer que os esforços teóricos que articulariam ação e estrutura emergem com vigor no cenário epistemológico contemporâneo.

Nestes termos, o movimento pós-estruturalista, iniciado na segunda metade do século XX, foi denominado em virtude da concepção ampla e subjetiva aos atores sociais, em contraste aos preceitos da corrente de pensamento estruturalista vigente neste período, a qual abordava a realidade social como um conjunto formal de relações, formando, dessa maneira, uma estrutura rígida e conservadora.

\footnotetext{
5 Em resumo, o maio de 1968 foi um evento político e reivindicatório, ocorrido nas ruas de Paris, no mês de maio 1968, que iniciou reunindo estudantes que protestavam por melhorias educacionais; além disso, posteriormente os trabalhadores franceses também se somaram às manifestações. "Como um herdeiro de 1968, o pós-estruturalismo defende a espontaneidade, a fluidez e a abertura nos movimentos políticos de resistência; a revolução do desdobramento dos limites se estende a estruturas e metas revolucionárias" (WILLIAMS, 2000, p. 39).

6Quando falamos em falsos dualismos, estamos destacando a crítica dos pensadores pós-estruturalistas que afirmavam que não há separação total entre ação e estrutura, mas sim uma articulação entre elas.
} 
Neste sentido, conforme Peters (2000), o pós-estruturalismo caracteriza-se por guardar certo ceticismo em relação ao sujeito autônomo e à autoconsciência, bem como à perspectiva de ter a razão como fundamento para compreender a ação humana. Em outros termos, o pós-estruturalismo conforme o autor - apresenta uma série de críticas aos pressupostos universalistas da racionalidade e da liberdade do "eu", muito presentes no existencialismo, além do questionamento às "filosofias do sujeito" "que não levam em conta as condições externas de suas próprias possibilidades" (PETERS, 2000, p. 36).

Tais críticas devem-se ao fato de que enfatizar a autoconsciência absoluta é negligenciar o "outro" (aqueles que agem com base em critérios culturais divergentes). Embora as duras críticas à razão e ao seu universalismo ${ }^{7}$ sejam latentes nos pressupostos pós-estruturalistas, é importante ressaltarmos um ponto chave nesse debate.

Diante disto, Peters (2000) aponta que ao invés de utilizar a autoconsciência, os pós-estruturalistas destacam o desenvolvimento discursivo do "eu", além da localização do sujeito na história e na cultura.

Dentre as características do pós-estruturalismo, encontra-se também, diferentemente do estruturalismo, a perspectiva de analisar a história critica por meio da diacronia, ou seja, há um resgate da historicidade nos pressupostos pós-estruturalistas, além do questionamento à identificação das estruturas universais, comum a todas as culturas e à mente humana (PETERS, 2000). Ademais, o pensamento pós-estruturalista é contra o realismo epistemológico ${ }^{9}$, ou seja, a crença do "conhecimento como uma representação precisa da realidade" (PETERS, 2000, p. 37).

Frente ao exposto, podemos afirmar, então, que o pós-estruturalismo influenciou diversas áreas do saber, dado seu caráter teórico diversificado, quais sejam: a literatura, a arte, a política, a sociologia, a

7 É importante ressaltarmos que a crítica central ao sujeito da autoconsciência é característica do estruturalismo francês, mostrando, com isso, que o pós-estruturalismo ainda guarda certas semelhanças com a sociologia da estrutura.

8 "Sua corporeidade, sua temporalidade e sua finitude, suas energias inconscientes e libidinais" (PETERS, 2000, p. 36).

9 Compreendido aqui como a lógica positivista de ter no conhecimento científico a verdade total e absoluta dos fenômenos. filosofia etc. Neste sentido, autores como Kristeva, Derrida, Deleuze, Lyotard, Foucault, Guatarri, Laclau, entre outros, destacam-se como grandes representantes desse movimento intelectual contemporâneo. Por conta disto, Peters (2000) ressalta que é melhor olhar o pós-estruturalismo como uma complexa rede de pensamento que, por seu turno, aglutina inúmeras possibilidades de prática crítica.

Assim, "o pós-estruturalismo é, decididamente, interdisciplinar, apresentando-se por meio de muitas diferentes correntes" (PETERS, 2000, p. 29). Neste sentido, podemos dizer que, em verdade, existem "pós-estruturalismos" - dos mais "brandos" aos mais "radicais" - ou seja, há uma pluralidade de pressupostos, muitas vezes divergentes em alguns aspectos, que contribuem para a formação do movimento pós-estruturalista. Exemplo de pós-estruturalismo "radical" são teorias Pós-Fundacionalistas de Laclau e Derrida.

Neste sentido, o pós-fundacionalismo advoga pela existência do fundamento (uma verdade), no entanto, ele é precário, finito e contingente. Em outros termos, há um fundamento, porém ele não é último, eterno e transcendental como queira o estruturalismo de Levi-Strauss. É importante ressaltarmos a crítica que Derrida (2002) faz a esse fundamento transcendental que se coloca fora das relações estruturais. No seio desta perspectiva pós-fundacionalista, o fundamento é a busca da ordem, porém pode ser alterado a qualquer momento, pois não é instável, nem imóvel como no fundacionalismo.

Os pós-fundacionalistas partem da ideia de que esse fundamento precário é necessário para a construção do social, pois é com base nele que buscamos a ordem e a plenitude (a essência), que jamais serão alcançadas na sua totalidade, porque somos sujeitos de uma falta constitutiva. Isso significa dizer que somos sujeitos incompletos, ou seja, vivemos em constante busca do horizonte pleno, de um fundamento último que nos dará tranquilidade e completude para viver, mas que é inalcançável. Apesar desse fundamento pleno ser uma impossibilidade, ele é uma ausência necessária. Em linhas gerais, se existe uma essência nessa abordagem ela é a própria falta de essência, 
pois a essência última é inexistente, isto é, os fundamentos são apenas parciais.

\section{ASPECTOS EPISTEMOLÓGICOS DA SOCIOLOGIA DE PIERRE BOURDIEU}

Muitos pensadores destacaram-se na segunda metade do século XX, a partir de 1960, sobretudo na efervescência do movimento pós-estruturalista. Dentre eles, o sociólogo francês, Pierre Bourdieu. Assim como grande parte dos esforços intelectuais de sua época, Bourdieu viu-se confrontado com a dicotomia ação e estrutura. Em linhas gerais, o objetivo de Bourdieu era descobrir as estruturas mais profundas dos diversos mundos sociais que formavam o universo social, bem como os mecanismos que corroboram para sua reprodução e, também para sua reprodução (WACQUANT, 2008). Para tanto, Bourdieu baseou-se em alguns conceitos centrais para a compreensão de seu arcabouço teórico, quais sejam: campo, habitus, capital, dominação, legitimidade e violência simbólica.

Diante do exposto, o campo é caracterizado por ser o locus da força, onde dominantes (iniciados) e dominados (profanos) estão em conflito na busca pelo poder. Neste sentido, o campo é relativamente autônomo em relação ao espaço social, ou seja, possui suas próprias regras e leis sociais no que tange ao "jogo estrutural" ${ }^{10}$, como por exemplo, o campo da moda, da arte, da ciência etc. Dessa forma, Bourdieu (2004, p. 20) argumenta que:

A noção de campo está aí para designar esse espaço relativamente autônomo, esse microcosmo dotado de suas leis próprias. Se, como o macrocosmo, ele é submetido a leis sociais, essas não são as mesmas. Se jamais escapa às imposições do macrocosmo, ele dispõe, com relação a este, de uma autonomia parcial mais ou menos acentuada. E uma das grandes questões que surgirão a propósito dos campos (ou dos subcampos) científicos será precisamente acerca do grau de autonomia que eles usufruem. Uma das diferenças

10 "Qualquer que seja o campo, ele é objeto de luta tanto em sua representação quanto em sua realidade [...] 0 campo é um jogo no qual as regras do jogo estão elas próprias postas em jogo" (BOURDIEU, 2004. p. 29). relativamente simples, mas nem sempre fácil de medir, de quantificar, entre os diferentes campos científicos, isso que se chamam as disciplinas, estará, de fato, em seu grau de autonomia. (Grifo dos autores).

Assim, o campo é o lugar do poder, é o mundo social onde se dão as relações de força ${ }^{11}$ entre os agentes do campo. Segundo Philippe Corcuff (2001, p. 54), "cada campo é então, ao mesmo tempo, marcado pela distribuição desigual dos recursos e logo, por uma relação de força entre dominantes e dominados [...] os agentes se confrontam ali para conservar ou transformar esta relação de força". Tal relação de forças está relacionada ao capital, esse que por sua vez divide-se em capital simbólico, capital cultural, capital político, capital social e capital econômico. 0 capital nada mais é que a dimensão de ingresso (moeda) para adentrar num determinado campo, ou seja, para que um agente entre no campo científico, ele necessita estar munido de um capital simbólico característico daquele campo. Em síntese, quem possui mais capital (simbólico) ${ }^{12}$, domina as regras do jogo.

Conforme afirma Bourdieu (2004, p. 27),

Esse capital [...] repousa sobre o reconhecimento de uma competência, que, para além dos efeitos que ela produz e em parte mediante esses efeitos, proporciona autoridade e contribui para definir não somente as regras do jogo, mas também suas regularidades, as leis segundo as quais vão se distribuir os lucros nesse jogo [...].

Segundo Bourdieu (2004), a definição da estrutura do campo dá-se por meio da distribuição do capital entre os agentes que pertencem a determinado campo. Todavia, essa autoridade (dominação) é uma

11 "As diferentes classes e facções de classes estão envolvidas numa luta propriamente simbólica para imporem a definição do mundo social, mais conforme a seus interesses e imporem o campo das tomadas de posições ideológicas reproduzindo em forma transfigurada o campo das posições sociais" (BOURDIEU, 1989, p. 11).

12 É simbólico, pois um determinado tipo de capital - ser um empresário bem sucedido, por exemplo -funciona num campo específico - nesse caso, a economia. Em outras palavras, nem sempre um capital pode ser convertido em outro. Ser um grande empresário (ter esse capital econômico) não dá direito ao agente de comprar um título de Doutor. Ele não pode converter seu capital econômico em capital intelectual a partir da compra ilícita de um título acadêmico. 
violência simbólica. Em verdade, esta última, é legitimada pelos dominados, ou seja, é uma dominação vista como positiva e natural, de modo que o dominado desconhece seu caráter histórico e arbitrário, caracterizando, assim, a dupla dimensão de reconhecimento e desconhecimento da dominação.

O habitus nada mais é que as regras, os costumes e a cultura que influenciam o agir. Bourdieu (1998, p. 21) ressalta que "o habitus é esse princípio gerador e unificador que retraduz as características intrínsecas e relacionais de uma posição e um estilo de vida unívoco, isto é, em um conjunto unívoco de escolhas de pessoas, bens de práticas". Com efeito, precisamos atentar para a dupla dimensão do habitus, ou seja, ao introjetar as estruturas objetivas (interiorização) do campo, ao mesmo tempo, o agente externaliza sua subjetividade no mundo social (exteriorização).

Esse duplo movimento13 torna o habitus uma estrutura estruturada e uma estrutura estruturante. Em certa medida, o habitus além de ter a função de articular a subjetividade do agente com o campo, ainda "exprime, sobretudo, a recusa a toda uma série de alternativas 14 nas quais a ciência social se encerrou; a da consciência (ou do sujeito) e do inconsciente, a do finalismo e do mecanicismo etc" (BOURDIEU, 1989, p. 60).

Após apresentarmos - de forma sucinta - o arcabouço conceitual da teoria bourdiena, voltamos ao ponto chave que levou Bourdieu a buscar na articulação entre ação e estrutura a verdade antropológica da prática humana. Para Bourdieu, uma ciência total deveria afastar-se daquele estruturalismo no qual não havia espaço para ação e onde o sujeito era completamente passivo. Deveria, também, refutar o subjetivismo puro, característico do existencialismo e da fenomenologia, onde nada existe anterior ao ser e somente o ser é dotado de capacidade para doar sentido ao mundo.

Neste sentido, Bourdieu (2000, p. 63) argumenta que "em todos os casos, os utilizadores da palavra habitus inspiravam-se numa intenção teórica próxi-

13Interiorização do exterior e exteriorização do interior (CORCUFF, 2001) 14Todas essas alternativas que Bourdieu ressalta, vão desde as teorizações idealistas do sujeito cartesiano, passando pelo marxismo, até à fenomenologia e ao estruturalismo francês. ma da minha, que era a de sair da filosofia da consciência sem anular o agente na sua verdade de operador prático de construções de objeto". Com base nesse argumento e tendo em vista o caráter bidimensional do espaço social, Bourdieu desenvolveu, em sua teoria, uma união entre o estruturalismo e o construtivismo. Em outras palavras, o estruturalismo construtivista é o próprio caráter de articulação entre o objetivo e o subjetivo. Deste modo, conforme aponta Corcuff (2001, p. 48)

\begin{abstract}
Pierre Bourdieu define o 'construtivismo estruturalista' na junção do objetivo e do subjetivo: Por estruturalismo [...]. [Neste sentindo, Bourdieu afirma] que existem, no próprio mundo social [...], estruturas objetivas independentes da consciência e da vontade dos agentes, que são capazes de orientar ou de limitar suas práticas ou suas representações. Por construtivismo, quero dizer que há uma gênese social dos esquemas de percepção, de pensamento e ação constitutivos do que chamo de habitus, por um lado, e, por outro lado, das estruturas sociais e, em particular do que chamo de campo.
\end{abstract}

Em regras gerais, Bourdieu postulava que se fazia necessário, para o conhecimento efetivo de determinado fenômeno social, uma leitura dual da realidade. Primeiramente, a observação de primeira ordem, na qual o observador percebe aquilo que está dado externamente, aquilo que é material e diz respeito às estruturas. Esta leitura está ligada a uma dimensão da física social (positivo). A segunda leitura diz respeito à observação de segunda ordem, momento em que o observador capta a subjetividade do agir, o sentido da ação, as disposições dos agentes em um determinado espaço social.

Em verdade, temos que perceber que Bourdieu, com o objetivo de articular ação e estrutura, propõe uma sociologia que se posiciona entre a física social (realismo epistemológico) e uma fenomenologia social. É por esse motivo, esse "meio termo", que Bourdieu sublinhou que uma ciência total está para além de uma física social pura ou para uma fenomenologia social pura, evidenciando, com isso, a falsa antinomia entre ação e estrutura, propondo, dessa forma uma 
articulação entre ambas para a explicação do universo social. Colaborando com este argumento, Wacquant (2008, p. 31) afirma que:

\begin{abstract}
Uma ciência da sociedade, assim entendida como um 'sistema' bidimensional' de relações de poder e relações de significado entre grupos e classes, deve, necessariamente, efetuar uma dupla leitura. Ou para ser mais preciso, deve elaborar um conjunto de lentes analíticas de duplo enfoque que capacite as virtudes epistêmicas de cada leitura ao mesmo tempo em que escapa do vício das duas.
\end{abstract}

Mais uma vez, fica nítida a refutação de Bourdieu às leituras únicas do tecido social e às falsas antinomias que insistiam em confrontar a dimensão da ação (subjetivo) com a dimensão da estrutura (objetivo). Neste sentido, Wacquant (2008, p. 31), ao explicar o cerne da intenção de Bourdieu, argumenta que

\begin{abstract}
Uma ciência total da sociedade deve desprender-se tanto do estruturalismo mecânico que põe os agentes [inativos frente à sociedade] como do individualismo teleológico que só reconhece os indivíduos na forma de um 'supersocializado' ou nos disfarces mais ou menos sofisticados do homos economicus. Objetivismo e subjetivismo, mecanicismo e finalismo, necessidade estrutural e agenciamento individual são falsas antinomias. Cada termo dessas oposições reforça ao outro e todos eles se confabulam para ofuscar a verdade antropológica da prática humana.
\end{abstract}

Diante do exposto, podemos perceber que Bourdieu propôs um estruturalismo-construtivista, a fim de escapar do determinismo estruturalista, sem cair no sujeito cartesiano da autoconsciência. Em síntese, ele objetivou a articulação de uma Sociologia da estrutura com uma Sociologia da ação, tendo como perspectiva a ideia de que a realidade social é dual. Em verdade, as características da teoria de Pierre Bourdieu, as quais elencamos aqui, não poderiam enquadrá-lo no ideal estruturalista, tampouco no ideal existencialista, haja vista que o próprio autor refutou os postulados deterministas do objetivismo e do subjetivismo.

\section{ASPECTOS EPISTEMOLÓGICOS DA SOCIOLOGIA DE ANTHONY GIDDENS}

Semelhante às teorias e às reflexões de Pierre Bourdieu, o sociólogo britânico Anthony Giddens apresenta sua concepção acerca do tecido social, objetivando, assim, preencher, superar as lacunas deixadas pelos os objetivistas (pensadores positivistas como Durkheim) e os subjetivistas (como a fenomenologia de Husserl) no que concerne à explicação acerca do tecido social. Com base em referenciais teóricos das mais diversas áreas ${ }^{15}$, Giddens propõe a teoria da estruturação, com o objetivo de compreender as práticas sociais ordenadas no espaço e no tempo, bem como entender como se mantêm estáveis as relações sociais e a reprodução das práticas sociais. Seguindo a principal preocupação da teoria social, ou seja, a elucidação de processos concretos da "vida social", Giddens reavalia a dicotomia básica (indivíduo e sociedade) presente no contexto da teoria sociológica até o fim da década de 1960 - referindo-se, sobretudo ao funcionalismo e ao estruturalismo - as quais denomina de consenso ortodoxo.

Com base nisto, Giddens (2013) define como consenso ortodoxo a predominância, no período do pós-guerra, das posições positivistas e das filosofias da ciência natural no campo das ciências sociais. Segundo o autor, o consenso ortodoxo apresenta três influências básicas: A influência do positivismo, implicando a aproximação do modelo das ciências naturais sob às ciências sociais; influência do funcionalismo no que tange ao método; e por último, a influência da concepção de "sociedade industrial". Estes três elementos moldaram as correntes de pensamentos até o fim da década de 1960.

A constituição da estrutura, tento em vista que a te-

150 pensamento teórico de Anthony Giddens está baseado em diversos modelos teóricos, como por exemplo, a microssociologia de Erving Goffman, a etnometodologia de Garfinkel, a fenomenologia de Schutz , o estrutural-funcionalismo de Parsons, o funcionalismo de Merton, o estruturalismo de Saussurre e Levi-Sträuss, o pós-estruturalismo de Foucault e Derrida e a ontologia heideggeriana, além dos clássicos Marx, Weber e Durkheim (GIDDENS, 1996). 
oria da estruturação está calcada nos conceitos de estrutura, sistema e dualidade da estrutura, é baseada nas atividades humanas, sendo essas atividades, ao mesmo tempo, o meio para constituir a própria estrutura. Assim, Giddens (2013, p. 22) afirma que "uma das principais proposições da teoria da estruturação é que as regras e os recursos esboçados na produção e na reprodução da ação social são, ao mesmo tempo, os meios de reprodução do sistema (dualidade da estrutura)".

Assim, diferentemente da sociologia estrutural ( $d a$ estrutura), a qual entende que as propriedades estruturais da sociedade formam influências coercitivas sob a ação, a teoria da estruturação, proposta por Giddens, postula que a estrutura é coercitiva, mas também facilitadora da ação, sendo (a estrutura) definida por meio das regras e dos recursos (GIDDENS, 2013)

Neste sentido, a estrutura é dual, ou seja, ela caracteriza-se pela coerção e facilitação da ação, pela imposição de regras e disponibilidades de recursos, também pela recursividade das práticas sociais. Manifestando-se na presença de normas, poderes e significados, o conceito de estrutura remete-nos às regras e aos recursos implícitos na produção e na reprodução do sistema social. Em verdade, as propriedades estruturais organizam recursivamente as práticas sociais do sistema. Assim, o conjunto de regras e recursos são os aspectos mais importantes na articulação dos sistemas sociais em sua estrutura. Os sistemas reproduzem as relações dos agentes como práticas regulares, ao longo do tempo e do espaço, nos quais as instituições são as propriedades estruturais do sistema social (GIDDENS, 2013).

Em verdade, a estrutura liga-se aos aspectos mais duradouros dos sistemas sociais, refletindo, dessa forma, um conjunto de interações e princípios organizativos que existem em virtude de uma reprodução social em tempo e espaço indetermináveis. Com efeito, a continuidade só existe nas atividades reflexivas. Conforme salienta Giddens (2013, p. 28):

A estrutura refere-se, em análise social, às propriedades de estruturação que permitem a delimitação do tempo-espaço em sistemas sociais, às propriedades que possibilitam a existência de práticas sociais dis- cernivelmente semelhantes por dimensões variáveis de tempo e de espaço, e lhes emprestam uma forma 'sistêmica'. Dizer que estrutura é uma 'ordem virtual' de relações transformadoras significa que os sistemas sociais, como práticas sociais reproduzidas, não têm 'estruturas', mas antes exibem propriedades estruturais, e que a estrutura só existe como presença espaço-temporal, em suas exemplificações em tais práticas e como traços mnêmicos orientando a conduta de agentes humanos dotados de capacidade cognoscitiva. [...] Estrutura refere-se não só a regras envolvidas na produção e reprodução de sistemas sociais, mas também a recursos [...] Os mais importantes aspectos da estrutura são as regras e os meios recursivamente envolvidos em instituições. As instituições são, por definição, os aspectos mais duradouros da vida social.

Deste modo, não há estruturas instituídas de maneira pré-existentes, alheias às atividades dos agentes, como também não há ação subjetiva e unilateral. Qualquer referência ao sistema social que omita a ação do ator é tão deficiente quanto considerar as atividades humanas sem levar em consideração a sua conexão com o sistema social. Do mesmo modo que o ator social não é responsável pela criação dos sistemas sociais, estes últimos não podem ser concebidos sem a ação do agente. $A$ ação é transformada e reproduzida pela continuidade da própria práxis (GIDDENS, 2013).

Com base no exposto, a partir da dualidade da estrutura, que procura explicar a mediação da estrutura e a interação com o processo de reprodução social, podemos afirmar que a constituição da sociedade, bem como a sua produção e sua reprodução originam-se dos próprios atores sociais. As ações dos agentes, de caráter recursivo, consideradas como práticas sociais, situadas no tempo e no espaço, geram uma continua recriação e reprodução dos contextos que possibilitam estas ações, formando, em nossa interpretação, uma circularidade operativa.

Frente ao caráter recursivo que proporciona a recriação e a reprodução das ações, Giddens (2013) evidencia o papel da consciência ou da cognição na intervenção dos atores nas práticas sociais. Assim, tendo em vista a recursividade da ação, o autor aponta para a monitoração reflexiva das ações dos agentes, ou seja, os atores sociais são capazes de, por meio da 
monitoração de suas próprias ações, desenvolverem uma atividade intencionada, adquirindo uma compreensão e uma racionalidade mínima no que diz respeito à prática social. A racionalização da ação é, portanto, uma característica da conduta humana, ligada intimamente a sua intencionalidade. Deste modo, a racionalização e o monitoramento reflexivo ligam-se às motivações dos agentes (GIDDENS, 2013).

Ainda na esteira do arcabouço teórico da teoria da estruturação, temos que a intenção do agente é uma característica que distingue a ação da agência. Assim, agência "diz respeito a eventos dos quais um indivíduo é perpetuador, no sentido de que ele poderia em qualquer fase de uma dada sequência de conduta, ter atuado de modo diferente" (GIDDENS, 2013, p. 10). Diferentemente da agência, a ação refere-se à intencionalidade do agir a partir da monitoração reflexiva, sendo um processo contínuo, diferenciando-se ainda de atos, que, por sua vez, são constituídos por um único momento. Diante disso, as estruturas adquirem um duplo significado, ou seja, não devem ser entendidas apenas no sentido supraindividual e exterior ao sujeito, mas também, como algo interior e subjacente ao sujeito (GIDDENS, 2013)

Destacamos, a partir disto, a importância que Giddens oferece à cognição do agente. Segundo Giddens (2005), todos os atores sociais possuem um considerável conhecimento das condições e das consequências de suas ações na vida cotidiana. Apesar de grande parte das ações humanas estarem engendradas no fluxo da conduta do dia a dia, estes atores são capazes de descrever em termos discursivos o que fazem e as razões que impulsionaram suas ações. Com base nisto, Giddens afasta-se das concepções apresentadas até então pelo estruturalismo, incorporando ao sujeito a consciência de seus atos/atitudes (sujeito ativo).

Frente aos aspectos que poderiam facilmente enquadrar Giddens a uma abordagem de caráter estruturalista, principalmente se atentarmos para 0 fato da utilização da linguística ao formular a teoria da estruturação, Giddens demonstra aspectos que poderíamos chamar de Pós-Estruturalista. A linguagem, para Giddens, é estruturada socialmente, pois há características da utilização da linguagem que qualquer orador deve observar, como por exemplo, a fala em um determinado contexto. Contudo, as qualidades da linguagem apenas existem, uma vez que os indivíduos que a utilizam seguem apenas suas regras práticas. Em outros termos:

Para essa compreensão da língua, os linguistas não possuem o grau de autossuficiência que Saussure, a Escola de Praga, Chomsky e outros propalaram, nem faria muito sentido sustentar, como Lévi-Strauss algumas vezes pretendeu, que a vida social é "como uma língua'. A linguística não pode fornecer um modelo analítico da natureza da ação ou das instituições sociais, porque, fundamentalmente, ela só se explica graças à compreensão destas. A 'reviravolta linguística' não passa de um afastamento da linguística, concebida como uma disciplina de formação independente, rumo ao exame da coordenação mútua de língua e práxis. (GIDDENS; TURNER, 1999, p. 288).

Não obstante, para Giddens (1999), a linguagem está constantemente em processo de estruturação. Deste modo, ao fazer uso da linguística, o autor afasta-se do estruturalismo no momento em que incorpora a racionalidade e a compreensão às ações dos agentes, aproximando-se, assim, do Pós-Estruturalismo.

Neste sentido, observamos, a partir da teoria da estruturação, que toda a ação humana é realizada no contexto de uma estrutura social pré-existente, pré-determinada, baseada em regras variáveis do contexto em que ela ocorre. No entanto, a estrutura e as regras não são permanentes, mas sim, sustentadas e modificadas pela ação humana por meio da reflexividade no tempo e no espaço.

Podemos afirmar, então, diante do que foi exposto e diante do contexto teórico-epistemológico vigente até a década de 1960, que a teoria da estruturação para esta concepção teórica, toda a ação social pressupõe a existência da estrutura e, ao mesmo tempo, a estrutura pressupõe a ação, porque essa depende das regularidades do comportamento humano - cumpre com o objetivo de romper com o consenso ortodoxo presente nas teorias sociais, tornando-se um modelo teórico inovador, ao propor a articulação entre a ação e estrutura em um cenário que por muito tempo, imperou a dicotomia entre o subjetivo e o objetivo. 


\section{CONSIDERAÇÕES FINAIS}

Podemos identificar que o debate acerca do movimento intelectual Pós-Estruturalista é recente. Muitas são as contendas emergentes que tratam da definição do que é ou o que não pode ser o pós-estruturalismo. Neste sentido, percebemos que é possível argumentarmos, longe de querermos esgotar a discussão, que alguns pensadores do século XX, sobretudo a partir da década de 1960, estão efetivamente influenciados pela perspectiva pós-estruturalista.

0 movimento intelectual pós-estruturalista advém de uma desconstrução da linguística e da análise libertária, possibilitando uma ampla oportunidade de interpretação, examinando a escrita como fonte paradoxal da subjetividade, o que antes, no estruturalismo, era considerado secundário (LECHTE, 2002). Diante desta crítica realizada internamente ao estruturalismo, a corrente pós-estruturalista não é considerada propriamente como uma escola de pensamento, talvez por isso, a maioria dos autores - incluindo Bourdieu e Giddens - negam o "rótulo" de pós-estruturalistas.

Nestes termos, embora exista o argumento de que Pierre Bourdieu e Anthony Giddens encontram-se inseridos em uma abordagem de dimensão estruturalista e que eles, consequentemente, não se consideravam pós-estruturalistas, acreditamos que seus elementos epistemológicos, metodológicos e teóricos estão muito mais próximos de uma perspectiva pós-estruturalista do que qualquer outra vertente do pensamento sociológico. Tendo por base as principais características desses pensadores - a crítica às falsas antinomias, o caráter histórico da relação campo e habitus (diacronia), o estruturalismo construtivista que articula ação e estrutura, por parte de Bourdieu; o caráter de indeterminação (contingência) da ação dos agentes, a crítica feita ao consenso ortodoxo, a premissa de que a realidade social é dual (dualidade da estrutura), por parte de Giddens - podemos afirmar que Bourdieu e Giddens aproximam-se, de fato, do movimento intelectual pós-estruturalista.
Salientamos, retomando a característica plural do Pós-Estrutruralismo - a de ser formado por diversas matrizes do pensamento sociológico e filosófico, muitas vezes divergentes entre si -, que, indubitavelmente, Bourdieu e Giddens afastam-se do pós-estruturalismo (radical) Pós-Fundacionalista proposto por Laclau, Derrida e outros, aproximando-se daquilo que poderíamos denominar de Pós-Estruturalismo "brando". Porém, o foco na articulação entre ação e estrutura, entre o objetivo e o subjetivo, dando ênfase ao caráter diacrônico do social, a refutação do determinismo cartesiano (do sujeito) e do determinismo estrutural (estruturalismo francês) no que tange à explicação da sociedade, filiam Bourdieu e Giddens na lógica epistemológica de caráter pós-estruturalista.

Não obstante, apontamos para o fato de que se Bourdieu e Giddens não são, de forma alguma, pósestruturalistas, como apontam alguns críticos, tampouco podem ser vistos como estruturalistas, haja vista a centralidade da articulação entre o subjetivo e o objetivo no que diz respeito às relações sociais. Característica essa que refuta, efetivamente, qualquer determinismo, seja ele da ação ou da estrutura.

\section{REFERÊNCIAS}

BOURDIEU, Pierre. 0 poder simbólico. Lisboa: Difel, 1989.

BOURDIEU, Pierre. Razões práticas: sobre a teoria da ação. Campinas: Papirus, 1996.

BOURDIEU, Pierre. Os usos sociais da ciência: por uma sociologia clínica do campo científico. São Paulo: Unesp, 2004.

BOURDIEU, Pierre; WACQUANT, Loïc. Uma invitación a la sociologia reflexiva. Argentina: Século XXI, 2008. p.25-76.

COHEN, Ira J. Teoria da estruturação e práxis social. In: GIDDENS, Anthony; TURNER, Jonathan 
(Org.). Teoria social hoje. São Paulo: UNESP, 1999. p.393-446.

CORCUFF, Philippe. As novas sociologias: construção da realidade social. Bauru- SP: EDUSC, 2001.

CUIN, Charles-Henry; GRESLE François. História da sociologia. São Paulo: Ensaio, 1994.

DERRIDA, Jacques. A estrutura, o signo e o jogo no discurso das ciências humanas. In: DERRIDA, Jacques. A escritura e a diferença. 3.ed. São Paulo: Perspectiva, 2002. p.227-249.

GIDDENS, Anthony. 0 pensamento teórico na sociologia. Sociologia. Porto Alegre: Artmed, 2005. p.666-683.

GIDDENS, Anthony. A Constituição da sociedade. São Paulo: WMF; Martins Fontes, 2013.

\section{LECHTE, John. Cinquenta pensadores}

contemporâneos essenciais: do estruturalismo à pós-modernidade. Rio de Janeiro: Difel, 2002.

LIMA, Gilson. Sociologia na complexidade. Sociologias, Porto Alegre, ano 8, n.15, p.136-182, jan-jun. 2006.
PETERS, Michel. Pós-estruturalismo e filosofia da diferença. Belo Horizonte: Autêntica, 2000.

\section{PETERS, G.M. Percursos na teoria das práticas}

sociais: Anthony Giddens e Pierre Bourdieu. 2006. 269f. Dissertação (Mestrado em Sociologia) Universidade de Brasília.

RODRIGUES, Leo Peixoto. A (des)estruturação das estruturas e a (re)estruturação dos sistemas: uma revisão epistemológica crítica. In: RODRIGUES, Léo Peixoto; MENDONÇA, Daniel de (Org.). Ernesto Laclau e NiklasLuhmann: pós-fundacionalismo, abordagem sistêmica e as organizações sociais. Porto Alegre: EDIPUCRS, 2006. p.35-67

VANDENBERGHE, Frédéric. Teoria social realista: um diálogo franco-britânico. Belo Horizonte: UFMG, 2010.

WILLIAMS, James. Pós-estruturalismo. PetrópolisRJ: Vozes, 2012. 